\title{
Regional Technological Dynamism and Noncompete Clauses: Evidence from a Natural Experiment*
}

\author{
Thor Berger Carl Benedikt Frey
}

\begin{abstract}
In this paper, we examine the causal impact of enforceable covenants not to compete (CNCs) on labour market matching and the technological dynamism of regions. Exploiting the fact that the Michigan Antitrust Reform Act (MARA) of 1985 inadvertently repealed Michigan's prohibition on $\mathrm{CNC}$ enforcement, we show that technical professionals in Michigan became increasingly likely to switch industry relative to similar workers in other U.S. states after prohibition. Workers switching industries after the introduction of MARA also earned lower wages, implying that they shifted into technical fields where their skills from previous employment were less productive. Estimates further show that the technological dynamism of Michigan declined in tandem, as fewer workers shifted into new types of jobs associated with recent technological advances. These findings are consistent with the view that skilled professionals that are subject to CNCs are more likely to leave their field of work post-employment to avoid lawsuits.
\end{abstract}

JEL: J62, J24, O33, R11

Keywords: Industry switching, covenants not to compete, skill mismatch, human capital, technological dynamism

${ }^{*}$ Berger: Department of Economic History, School of Economics and Management, Lund University \& Oxford Martin School, University of Oxford. (E-mail: thor.berger@ekh.lu.se) Frey: Oxford Martin School, University of Oxford (E-mail: carl.frey@oxfordmartin.ox.ac.uk). We are grateful to the editor and two anonymous referees for comments and suggestions that substantially improved the paper. Berger gratefully acknowledges funding from the Swedish Research Council (\#20141491 ) and the Crafoord Foundation (\#2013-0812) and Frey gratefully acknowledges funding from Citi. The usual disclaimer applies. 


\section{Introduction}

Why are some regions more dynamic than others? Saxenian (1994) famously pointed at the high rates of employee mobility in Silicon Valley as one of the drivers behind its technological dynamism. ${ }^{1}$ According to Gilson (1999), much of this dynamism can be explained by an exceptional feature of California's legal infrastructure, introduced in the 1870s, making it impossible for employers to enforce covenants not to compete ("CNCs" or "noncompetes"): the California Civil Code of 1872 outlawed all covenants in employment contracts, restricting the ability of employees to switch to working for a competitor. Empirical support for this view is provided by Fallick et al. (2006), showing that labour mobility in the computer industry is relatively high in California in general, and in Silicon Valley in particular, compared to other cities and regions in the United States.

In this paper, we use the introduction of the Michigan Antitrust Reform Act (MARA) as a natural experiment to examine the causal impact of $\mathrm{CNC}$ enforcement policy on industry switching and the technological dynamism of regions. Following seminal work by Marx et al. (2009), we take advantage of the fact that the MARA inadvertently repealed the 1905 prohibition on CNC enforcement, making Michigan's noncompete reversal a unique exogenous event. Our analysis builds on the simple intuition that $\mathrm{CNCs}$ restrict job switching between competing companies within the same industry and thus the reallocation from contracting firms to expanding innovators that value their skills. As a result, we predict that workers separating from their employer are more likely to switch industry after the introduction of the MARA. Figure 1 is suggestive of such a tendency, showing a relative increase in industry switching in Michigan after 1985, based on data for technical professionals from the Current Population Survey (CPS) samples. ${ }^{2}$

In our empirical analysis, we use a differences-in-differences approach to show that industry switching indeed increased significantly in Michigan after the passing of the MARA relative to other U.S.

\footnotetext{
${ }^{1}$ We refer to the reallocation of talent towards towards innovating companies as "technological dynamism" and "industrial renewal" interchangeably.

${ }^{2}$ As we discuss below, technical professionals include occupations such as computer scientists, engineers, and natural scientists. Because we are interested in the technological dynamism of regions, and CNCs typically mainly concern employees with specific technical knowledge, we restrict our analysis to technical professionals. Furthermore, as technical professionals can be employed in different industries, but are unlikely to switch occupation (a computer scientist is unlikely to become a dentist, for example, but may well work in the financial industry as well as the computer industry), we restrict our analysis to industry switching, rather than occupational switching.
} 


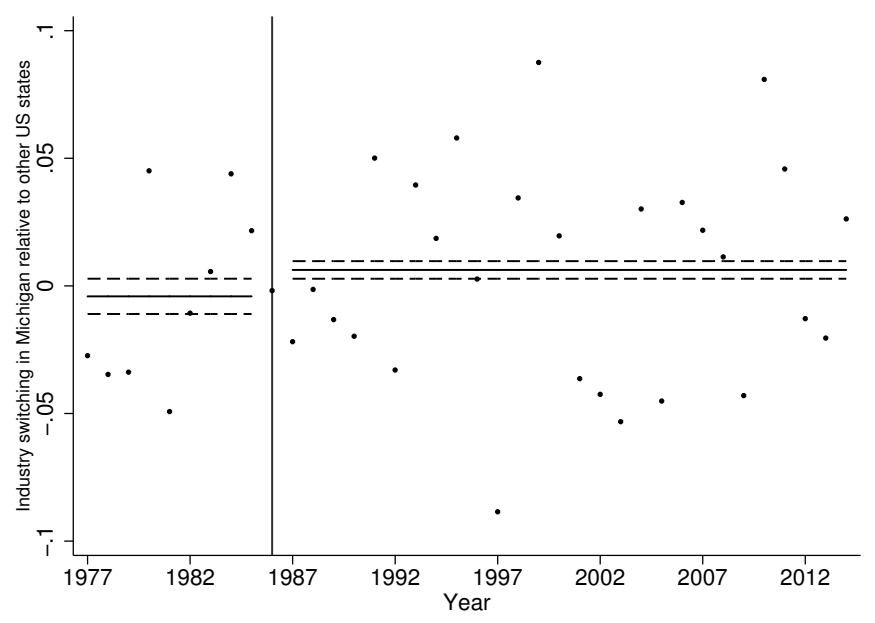

Notes: This figure shows annual differences between the share of technical professionals that changed detailed industry on a year-on-year basis in Michigan and technical professionals changing industry in all other states between 1977 and 2014 based on data from the CPS samples. A vertical line denotes the year the MARA was passed and estimated average differences in industry switching before and after the passing of MARA are denoted by solid lines with a 95-percent confidence interval denoted by dashed lines.

Figure 1: Industry switching in Michigan relative to other states, 1977-2014.

states, while there was no observable differences in industry switching prior to the introduction of the MARA. These estimates are robust to using a wide range of individual- and state-level controls as well as various control groups, including workers in states that did not enforce CNCs at the time of Michigan's reversal, geographically proximate states, and states that are matched on a range of pre-treatment characteristics. Workers switching industries also earned lower wages than observationally similar workers in other states, implying that workers have acquired some skills in employment which are less productive in other industries. Our findings are thus suggestive of increased skills mismatch in Michigan after the introduction of the MARA.

We next proceed to examining the impact of the MARA on the technological dynamism of Michigan. Because enforceable CNCs restrict the reallocation of workers towards innovators within the same industry, we predict a decline in technological dynamism in Michigan. While the CPS data does not allow us to track the movement of workers across companies within the same industry, we employ a novel approach to examine worker reallocation within various technical fields. Using data from revisions of the Dictionary of Occupational Titles (Lin, 2011), we isolate new job titles emerging as a result of technological advances. Estimating the share of workers employed in new types of jobs, we are able to track the tech- 
nological dynamism of Michigan before and after the MARA. ${ }^{3}$ Doing so, we document that workers in Michigan were less likely to shift into new employment opportunities in their technical field subsequent to the MARA. Taken together, these findings are consistent with survey evidence showing that skilled professionals that are subject to CNCs are more likely to leave their technical field post-employment to avoid potential lawsuits (Marx, 2011), as well as studies suggesting that noncompetes reduce labour mobility within industries (Fallick et al., 2006).

The present study relates to two literatures. First, it builds on the literature emphasizing the benefits of labour market pooling, allowing workers to move across firms to find the best match for their skills (Marshall, 1920; Helsley and Strange, 1990). In particular, Ellison et al. (2010) show that industries using the same type of workers tend to co-locate and Bleakley and Lin (2012) find that larger cities exhibit lower rates of occupation and industry switching, implying better matching in thicker labour markets. Yet even in thicker labour markets barriers to occupational choice can result in substantial misallocation: since the Civil Rights movement of the 1960s, 15 to 20 percent of growth in output per worker in the U.S. can be explained by the improved allocation of talent (Hsieh et al., 2013). Relative to this literature, we use a natural experiment to examine the causal impact of one particular barrier to industry choice, focusing on the relationship between the presence of enforceable CNCs and labour market matching.

Second, we extend the literature examining the legal infrastructure underlying employee mobility. For example, Fallick et al. (2006) find evidence supporting the view that California's prohibition of CNCs enhances mobility and agglomeration economies in the computer industry, relative to other U.S. cities and regions. While they are unable to rule out the possibility of this relationship being driven by some intermediating factor, such as business culture, Marx et al. (2009) uses the introduction of MARA to examine the causal relationship of CNCs on inventor mobility, finding that its introduction significantly reduced the mobility of patent applicants. In a similar manner, we use the introduction of the MARA as a natural experiment to examine the impact of $\mathrm{CNCs}$ on labour market matching and the technological dynamism of regions, rather than the geographical mobility of inventors.

\footnotetext{
${ }^{3}$ A growing share of workers employed in new jobs from year-to-year is indicative of more rapid reallocation within a technical field.
} 
Third, we build on a vast literature on industrial renewal (Hansen, 1939; Schumpeter, 1939; Kindleberger, 1961; Jacobs, 1969). For example, in a seminal review of urban development Jacobs (1969) famously suggested that the long-run growth of cities hinges on their ability to create new jobs and industries. Berger and Frey (2015) further document a strong relationship between human capital abundance and job creation in new industries across U.S. cities. Similarly, Glaeser (2005) show how human capital shaped the industrial renewal process in Boston, since its formation in 1630. We add to this literature by documenting that technological dynamism also critically depends on the legal infrastructure of regions: enforceable noncompetes reduces labour mobility and thus industrial renewal.

The remainder of this article is structured as follows. First, we review the literature about noncompetes and MARA, outline our predictions, and describe our data sources. In the third part we provide empirical evidence about the labour market impacts of MARA. Finally, we derive some conclusions and implications for policy.

\section{Noncompetes and Technological Dynamism}

In this section, we examine Michigan's inadvertent repeal of its prohibition on CNC enforcement, and discuss the expected labour market impacts of MARA. We then go on to describing our data sources.

\section{The Michigan Antitrust Reform Act}

The introduction of the MARA was an unanticipated and seemingly exogenous event, allowing us to exploit Michigan's CNC enforcement policy reversal to identify the causal impact of noncompetes on labor market matching and technological dynamism. Prior to the MARA, CNC enforcement in Michigan had long been governed by Public Act No. 329 of 1905, making all noncompetes illegal and void. Unless the information possessed by the employee was considered a trade secret, workers had unrestricted mobility. Since the statute's enactment in 1905, this area of the law did not develop in Michigan (Pynnonen, 1994). Thus, the introduction of the MARA in 1985, which repealed the 1905 statute, constituted a watershed in the history of Michigan's CNC enforcement policy.

Nevertheless, the purpose of the MARA was not to alter CNC legislation, but to make antitrust law complaint with the Uniform State Antitrust Act (Lifland, 1984). For example, the legislative analysis of 
the House and Senate subcommittees in Michigan does not include any mention of CNC enforcement policy constituting a motivation for the bill (Bullard, 1985). A detailed account of the motivation behind MARA is also provided by Marx et al. (2009), showing that Public Act No. 329 was repealed due to its antitrust implications and did not stem from any desire to make changes to CNC legislation in Michigan. In particular, interviews conducted with active Michigan-based labour lawyers at the time suggests that the MARA repeal of CNC enforcement was unintentional, and a review of law journals just prior to 1985 shows that there was no debate surrounding Michigan's CNC policy. However, several articles appeared just after the reversal (Alterman, 1985; Levine, 1985; Sikkel and Rabaut, 1985).

We proceed to outlining our predictions for the impact of MARA on labour market matching and the technological dynamism of Michigan.

\section{Conceptual Framework}

Employers increasingly add CNCs to employment contracts to restrict their employees from forming or joining competing companies after the working relationship is terminated. According to recent survey evidence, nearly half of technical professionals across industries in the U.S. are subject to CNCs (Marx, 2011). While noncompetes can take many different forms, they typically include a list of competitors or technical fields where one may not work for a defined period of time after leaving the company. The implications of such arrangements for workers are nicely illustrated by the case of Kai-Fu Lee, a speech recognition engineer working for Microsoft. When Lee left the company for Google in 2005, Microsoft filed a lawsuit for violation of an existing CNC. As a result, the Washington state Superior Court issued a temporary restraining order, prohibiting Lee from working on Google projects competing with Microsoft. In other words, $\mathrm{CNCs}$ provide a way for firms to reduce knowledge spillovers resulting from frequent job-hopping. As suggested by Acemoglu (1997), the costs of such spillovers can be substantial even when all human capital is general and no specific information about technologies and trade secrets is leaked. Because noncompetes reduce the probability of an employee working for a new employer in the near future, CNCs may induce firms to invest more in human capital. ${ }^{4}$

\footnotetext{
${ }^{4}$ Nonetheless, Garmaise (2011) shows that R\&D expenditure per capita tends to be lower where firms are not prohibited from using noncompetes, suggesting that $\mathrm{CNC}$ enforcement policy does not reduce investment in the creation of new knowledge.
} 
An implicit assumption in Saxenian (1996) account of Silicon Valley is that the benefits of knowledge spillovers exceed the costs, leading companies to cluster. Because a large fraction of the cost of adopting new technologies arises from a lack of information regarding the range of available technologies and their respective profitability, slowing down their diffusion (Griliches, 1957; Mansfield, 1961), the presence of knowledge spillovers or imitation across firms will result in faster diffusion rates in cities and regions that initially adopt a new technology. ${ }^{5}$ Nevertheless, firms may find it individually desirable to exercise CNCs even if this reduces the technological dynamism of the industrial cluster. If that is the case, we should expect to see lower mobility and less technological dynamism in clusters where noncompetes are enforceable. Accordingly, we predict that since the introduction of MARA workers in Michigan are: (i) less likely to take on new employment opportunities in their technical field; and (ii) more likely to switch industry to avoid potential lawsuits.

Furthermore, barriers to industry choice have implications for the productive allocation of talent. While early work on human capital typically focused on skills that are specific to a particular company, or completely general (Becker, 1975; Mincer, 1958), there is growing evidence that many skills are industry specific. For example, Neal (1995) and Parent (2000) show that workers are compensated for skills that are particular to their industry, rather than general or firm-specific ones, and Sullivan (2010) finds that industry specific human capital provides a key determinant of wages. In particular, displaced workers that find a new job in the same industry, earn significantly higher wages than workers that switch industries following displacement (Neal, 1995). ${ }^{6}$ The importance of industry specific skills is also captured by the very nature of $\mathrm{CNCs}$, which typically prohibit workers to work for competitors in the same industry for a specified period of time post-employment. Workers that switch industries to avoid lawsuits, rather than seeking a better opportunity, are likely to face a worse match for their skills because the skills of a worker from previous employment are likely to be less productive in another industry. We therefore predict that: (iii) workers leaving their technical field post-MARA in Michigan are likely to earn lower wages relative to observationally similar workers in other U.S. states.

\footnotetext{
${ }^{5}$ A large literature documents the slow diffusion of new technologies (Grübler, 1991; Jovanovic and Lach, 1997; Comin and Hobijn, 2010). Also see Goolsbee and Klenow (2002) that provide evidence of spillovers in computer adoption among individuals.

${ }^{6}$ The relative importance of firm, occupation and industry specific skills nevertheless remains a debated topic (Poletaev and Robinson, 2008; Kambourov and Manovskii, 2009; Gathmann and Schönberg, 2010)
} 


\section{Data}

To systematically analyze patterns in industry switching, we use annual data from the CPS samples for the period 1977 to 2014, limiting our sample to employed workers aged 25 to 65 , excluding workers in agricultural, military, and public administration jobs (Flood et al., 2015). ${ }^{7}$ Furthermore, we limit our analysis to technical professionals, for which CNCs are likely to be most prevalent. ${ }^{8}$ Crucially, the CPS samples report a worker's detailed industry for the current and previous calendar year thus allowing us to capture if a worker changed industries. ${ }^{9}$ Using these variables we create a dummy taking the value 1 if a worker changed detailed industry since last year, while taking the value 0 if a worker remained in the same industry. Figure 1 shows the share of workers in Michigan that changed detailed industry on a year-on-year basis between 1977 and 2014 relative to those in other states, from pooled cross-sections of the CPS data.

As a measure of technological dynamism, we match data on the appearance of new occupational titles from Lin (2011) to the CPS worker-level samples, using 1990 SOC codes. Lin (2011) compares the fourth (1977) and the revised fourth (1991) edition of the Dictionary of Occupational Titles (DOTs) to isolate new job titles that appeared for the first time during this period. In the 1991 edition, some 830 out of a total of 12,741 titles that relate directly to technological innovations appeared for the first time. Examples of new titles include database administrators, programmer-analysts, and special procedures technologists, MRI. However, while new job titles are reported at the 6-digit level, the CPS samples only report detailed occupations. For each detailed occupation we thus observe the share of new titles within each detailed occupation, which is interpreted as the probability that a workers is employed in a new job by assuming that the distribution of new titles and employment is similar across detailed occupations. ${ }^{10}$

We limit our analysis to the post-1977 period as we are only able to track the emergence of new jobs since then. Results reported below are, however, very similar in a sample that also includes years prior to 1977.

\footnotetext{
${ }^{8}$ More precisely, our samples are restricted to the detailed occupations Engineers, Mathematical and Computer Scientists, and Natural Scientists.

${ }^{9}$ If a respondent held more than one job in the previous year, the job that lasted longest is reported. We rely on the contemporaneous codes (IND/INDLY), though we show below that using the consistent classification system, based on 1950 codes, provided by the IPUMS produces very similar results.

${ }^{10}$ While this assumption is unlikely to hold to the extent that new industries tend to start out small, such a violation would introduce little bias in a cross-state analysis. Indeed, Lin (2011) provides a wide range of robustness checks showing that such an assumption is an unlikely source of bias.
} 


\section{Empirical Analysis and Results}

To examine the labour market impact of Michigan's CNC enforcement reversal, we use a differencein-differences approach allowing us to compare how outcomes changed for technical professionals in Michigan following the introduction of the MARA relative to observationally similar workers in other states. Specifically, we estimate regressions of the following form:

$$
y_{i s t}=\alpha_{s}+\lambda_{t}+\mathbf{X}_{\mathrm{ist}} \zeta+\delta\left(M A R A_{s} \times \text { Post }_{t}\right)+\varepsilon_{i s t}
$$

where $y$ is an outcome for an individual worker $i$ located in state $s$ in year $t$, which in the main analysis corresponds to a dummy taking the value 1 if a worker changed detailed industry between $t$ and t-1. $M A R A_{s}$ is a dummy taking the value 1 for Michigan and 0 for other states, which is interacted with Post $_{t}$ that takes the value 1 for years after 1986 and 0 for years before. ${ }^{11}$ Our main parameter of interest is $\delta$, capturing how outcomes changed for technical professionals in Michigan relative to those in other states, before and after Michigan's CNC enforcement reversal. A caveat with this approach, however, is that we do not observe which workers are actually bounded by $\mathrm{CNC}$ agreements, which gives these estimates an intent-to-treat flair. For the statistical inference, we cluster standard errors at the state level throughout our analysis (Bertrand et al., 2004).

To capture factors that may determine rates of industry switching that are time-invariant but specific to each state, we include a full set of state fixed effects $\left(\alpha_{s}\right)$ and to take into account that aggregate rates of switching are affected by macroeconomic factors, such as business cycle fluctuations, we include a full set of year effects $\left(\lambda_{t}\right)$ that capture national variations in industry switching over time. Furthermore, the probability of industry transitions is associated with individual characteristics; for example, younger workers with less industry-specific human capital are more likely to change industries (Bleakley and Lin, 2012). To account for this, we include several individual characteristics in the vector $\mathbf{X}_{\text {ist }}$, including a quartic in age, an indicator for sex and whether a worker is married respectively, as well as a dummy for whether a worker has a bachelor's degree or four years of college education. Additional estimations

\footnotetext{
${ }^{11}$ While the MARA was formally passed in 1985, we use 1986 to designate the year of treatment due to how our industry transition variable is constructed: we observe a worker in year $t$ and whether or not that worker changed industry between year $t-1$ and $t$. However, results remain very similar if we instead use the year 1985 as the treatment cutoff.
} 
also include a full set of detailed industry fixed effects, which capture differences in industry switching across industries, and state-level economic factors that may affect the probability of an individual worker changing industry.

\section{Results}

In this section, we show that while technical professionals in Michigan did not switch industries more or less frequently than similar workers in other U.S. states prior to the introduction of the MARA, technical professionals in Michigan experienced higher rates of industry switching relative to workers in other states after the passing of the MARA. In tandem with this shift, workers switching industries in Michigan experienced relative real wage declines and were also less likely to be observed in new jobs associated with technological advances in their technical field after the introduction of MARA.

\section{Industry switching}

Table 1 shows average rates of industry switching in Michigan and four alternative control groups before and after the introduction of the MARA. ${ }^{12}$ Importantly, while rates of industry switching were typically marginally lower than in other other states prior to Michigan's policy reversal, switching was higher relative to all other control groups after 1985. To provide further supporting evidence of few pre-existing differences in industry switching, column 1 of Table 2 presents estimates from regressing our industry transition measure for the period 1977-1986 on a dummy variable taking the value 1 for Michigan and 0 for other states. ${ }^{13}$ Reassuringly, estimated average differences in rates of industry transitions for technical professionals located in Michigan relative to workers in other states are close to zero and not statistically significant prior to the introduction of the MARA, which lends further support to the argument that Michigan's enforcement policy reversal was an exogenous event.

\footnotetext{
${ }^{12}$ We describe the construction of these control groups in more detail below.

${ }^{13}$ Below we present robustness checks of our main results restricting the sample to states that did not enforce CNCs at the time of Michigan's reversal. Comparing differences in industry changes against these states in the pre-MARA period similarly produces no statistically significant differences in industry transitions for Michigan workers (the OLS estimate is -0.009 , with a standard error of 0.007).
} 


\begin{tabular}{lccccc} 
Period & Michigan & All other states & No CNCs & Adjacent states & Matched states \\
\hline Pre-MARA (1977-1985) & 0.055 & 0.058 & 0.066 & 0.049 & 0.056 \\
& $(0.228)$ & $(0.234)$ & $(0.248)$ & $(0.216)$ & $(0.229)$ \\
Post-MARA (1986-2014) & 0.130 & 0.122 & 0.120 & 0.118 & 0.119 \\
& $(0.336)$ & $(0.327)$ & $(0.325)$ & $(0.322)$ & $(0.325)$ \\
\hline
\end{tabular}

Notes: This table report averages (standard deviations) of the share of technical professionals in the CPS samples that changed detailed industry on a year-on-year basis in Michigan and four alternative control groups: (i) all other US states; (ii) those states that did not enforce CNCs at the time of Michigan's reversal; (iii) a sample of geographically adjacent states; and (iv) a control group consisting of states that had similar propensity scores based on a range of pre-treatment characteristics. See the main text for a more detailed description of each respective control group.

Table 1: Average rates of industry switching before and after the MARA.

After the introduction of the MARA, workers in Michigan became increasingly likely to change detailed industry relative to similar workers in other states. Table 2, columns 2 and 3 presents estimates of equation (1) excluding and including individual controls respectively, showing that the probability of technical professionals changing industry increased by about one percentage point in the post-MARA period relative to observationally similar workers in other states. ${ }^{14}$ This accounts for about a tenth of the mean industry switching across U.S. states - a sizable effect considering that about half of technical professionals in the U.S. are subject to CNCs (Marx, 2011).

Estimated increases in industry switching may, however, reflect factors specific to the Michigan economy other than the introduction of the MARA. To that end, columns 4-6 add additional controls to account for some of these potential explanations. First, column 4 includes annual state-level changes in employment in the auto industry and the manufacturing sector respectively, average incomes, and unemployment rates. ${ }^{15}$ Although these controls reduce the estimated relative increase in industry switching, it remains positive and statistically significant at the 10-percent level. Secondly, a standard concern in a difference-in-differences analysis is that treatment effects reflect pre-existing trends, though we note that there is little evidence of meaningful differences in average rates of industry switching prior to the introduction of the MARA (see Table 1). To further mitigate such concerns, however, we include a full set of linear state trends in column 5, capturing trend differences in industry switching over the period. Estimated increases in industry switching increase substantially in Michigan, suggesting a negative trend

\footnotetext{
${ }^{14}$ Throughout the analysis we present OLS estimates, but note that both logit and probit estimates produce the same qualitative results.

${ }^{15}$ These variables are derived from the CPS samples.
} 
(1)

Pre-MARA

Michigan (=1)

MARA $_{s} \times$ Post $_{t}$

Observations

9,823

Individual controls?

State controls?

State trends?

Industry FE?

(0.003)

(3)

(2)

Worker ce

Worker controls

(4)

(5)

(6)

(7)

State Controls

State Trends

Industry FE

Alternative codes

$\begin{array}{cccccc}0.011^{* * *} & 0.010^{* *} & 0.007 * & 0.051 * * * & 0.049 * * * & 0.067 * * * \\ (0.004) & (0.004) & (0.003) & (0.002) & (0.003) & (0.002)\end{array}$

$60,950 \quad 60,950$

60,950

60,950

60,950

60,950

No

Yes

Yes

Yes

Yes

Yes

No No

Yes

Yes

Yes

Yes

No No

Yes

Yes

Yes

No No

No No Yes

Yes

Notes: Column 1 reports a regression of industry switching rates on a dummy taking the value 1 for Michigan for the preMARA period and columns 2-7 report OLS estimates of $\delta$ from equation (1), where the left-hand side variable is a dummy variable taking the value 1 if a worker changed detailed industry since last year and 0 otherwise. All regressions are weighted using the CPS weights and include a full set of state and year fixed effects. State controls include: annual changes in changes in employment in the auto industry and the manufacturing sector respectively, average incomes, and unemployment rates. Column 7 uses the alternative IND1950 classification scheme to categorize industry switches. Statistical significance based on robust standard errors clustered at the state-level is denoted by: $* * * \mathrm{p}<0.01, * * \mathrm{p}<0.05, * \mathrm{p}<0.10$.

Table 2: Industry switching after the MARA, 1977-2014.

in industry switching relative to other states. Third, column 6 further adds a full set of detailed industry fixed effects, showing that industry switching increased also within industries after the introduction of the MARA. An additional concern is that Michigan's historical dependence on the auto industry may influence the results. To further alleviate concerns that the auto industry drives the results we have estimated changes in industry switching excluding the auto industry. While excluding the auto industry slightly deflates the relative increase in technical professionals changing industries, a large, positive, and statistically significant effect remains. ${ }^{16}$ As a final robustness check, we use a consistent definition of detailed industries using the 1950 codes provided in the CPS data to confirm that our results are not driven by spurious changes in industry classifications over time (column 7). Yet, because we are comparing the impact of a policy change in Michigan relative to other states, a remaining concern is that the group of control states may differ across several dimensions that we do not capture with our control variables, which means that our estimates may still reflect factors other than the introduction of MARA.

To further alleviate concerns that our estimates reflect factors that are unique to the Michigan economy, Table 3 presents our estimates using four alternative control groups. As above, we first compare

\footnotetext{
${ }^{16}$ Excluding the auto industry and estimating the equivalent to column 6 in Table 2 yields an OLS estimate (s.e.) of 0.030 (0.003), which is slightly smaller than when including the auto industry though still positive and statistically significant.
} 
workers in Michigan relative to workers in all other states for reference. Column 2 then reports estimates from comparing changes in industry switching in Michigan relative to geographically proximate states that constitute a relevant control group to the extent that proximate states are more likely to have a similar industrial specialization and be affected by similar local economic shocks. ${ }^{17}$ Estimated increases in industry switching are marginally smaller, though such differences are not statistically significant. We next provide similar estimates in a sample where the control group is limited to those states that did not enforce CNCs at the time of Michigan's reversal as in Marx et al. (2009). ${ }^{18}$ Workers in Michigan experienced higher rates of industry shifting also relative to workers in states that left their CNC enforcement policy unaltered, providing further evidence that the increase in industry switching in Michigan was related to $\mathrm{CNC}$ legislation. Furthermore, estimated relative changes in workers switching industries are slightly larger, suggesting that a comparison of industry transitions against all other U.S. states, if anything, tends to underestimate the impact of Michigan's policy reversal. Finally, we create a matched control group of states matching on propensity scores based on state-level college shares, the share of technical professionals in the labor force, the share employment in manufacturing, and average incomes, all averaged over the pre-treatment period. Again, the estimated increase in industry switching reported in column 4 is virtually identical to when considering all other states as a control group. ${ }^{19}$

Taken together, our regression results suggest that the enforcement of CNCs led to a higher incidence of workers taking employment in industries other than those in which they were previously employed as Michigan reversed its policy due to the passage of the MARA. A related hypothesis is that professionals in Michigan would be more active in searching for a job in the same industry in another state after 1985. To examine this hypothesis, we combine the available information in the CPS samples on whether a worker has migrated across state borders over the past year and the state of residence last year to calculate the share of technical professionals that moved away from Michigan before and after the introduction of the MARA. While some 2.8 percent of technical professionals in other U.S. states originated from

\footnotetext{
${ }^{17}$ The group of geographically proximate or "adjacent" states consist of: Illinois, Indiana, New York, Ohio, Pennsylvania, and Wisconsin.

${ }^{18}$ These states include Alaska, California, Connecticut, Minnesota, Montana, North Dakota, Nevada, Oklahoma, Washington, and West Virginia (Malsberger, 1996; Marx et al., 2009).

${ }^{19}$ We include states with non-zero propensity scores, which are: Alabama, California, Connecticut, Delaware, Illinois, Indiana, Michigan, New Jersey, New York, Ohio, Oregon, Pennsylvania, Rhode Island, Washington, West Virginia, and Wisconsin.
} 
(1)

\begin{tabular}{ll} 
& All state \\
\hline MARA $_{s} \times$ Post $_{t}$ & $0.059 * * *$
\end{tabular}

(0.001)

Observations

60,950

Number of states

(2)

(3)

(4)

\begin{tabular}{ccc} 
Adjacent states & States with no CNC & Matched states \\
\hline $0.057 * * *$ & $0.061 * * *$ & $0.059 * * *$ \\
$(0.002)$ & $(0.001)$ & $(0.001)$ \\
11,707 & & \\
7 & 15,684 & 29,688 \\
& 11 & 17
\end{tabular}

Notes: This table report OLS estimates of $\delta$ from equation (1), where the left-hand side variable is a dummy variable taking the value 1 if a worker changed detailed industry since last year and 0 otherwise. All regressions are weighted using the CPS weights and include a full set of individual controls described in the main text, state fixed effects and linear trends, and year fixed effects. Column 1 report estimates using all U.S. states as a control group, while columns 2-4 presents estimates restricting the control states to geographically proximate states, states that did not enforce CNCs at the time of Michigan's reversal, and a matched control group respectively. See the main text for a further description of these alternative control groups. Statistical significance based on robust standard errors clustered at the state-level is denoted by: $* * * \mathrm{p}<0.01$, $* *$ $\mathrm{p}<0.05, * \mathrm{p}<0.10$.

Table 3: Industry switching after the MARA, 1977-2014: Alternative control groups.

Michigan during the five years prior to the MARA, that share increased to 4.2 percent in the five years following Michigan's reversal. ${ }^{20}$ Although the relatively few observations available should caution the interpretation of these results, they are consistent with technical professionals increasingly seeking out job opportunities in other states to evade the enforcement of CNCs as Michigan introduced the MARA.

More broadly, while our estimates do not capture the extent of human capital losses due to skill mismatch as workers changed industries, they are suggestive of barriers to industry choice leading to potentially inefficient labour market outcomes. We next provide some evidence of this, showing that professionals in Michigan that changed industries experienced relative real wage declines and were less likely to transition into employment in new types of jobs after the introduction of the MARA.

\section{Wage impacts and technological dynamism}

Technical professionals in Michigan were not bounded by CNCs prior to the introduction of the MARA, making inter-industry transitions more likely to reflect a productive reallocation of human capital. After Michigan's policy reversal, however, the enforceability of CNCs may have pushed workers into industries where their skills were less productive. In that case, industry switching should result in lower wages for

\footnotetext{
${ }^{20}$ We cannot calculate the share of technical professionals crossing state borders prior to 1982 since the CPS samples do not report state of residence prior to this date. Between 1982 and 1990 we observe a total of 590 technical professionals that migrated across states in the past year. Unfortunately, the number of observations is to small to provide meaningful estimates of changes in the share of migrants that switched and remained in their industry respectively.
} 


\begin{tabular}{lccc} 
& $(1)$ & $(2)$ & $(3)$ \\
\hline MARA $_{s} \times$ Post $_{t}$ & -0.103 & $-0.178^{* * *}$ & $-0.224 * * *$ \\
& $(0.065)$ & $(0.059)$ & $(0.072)$ \\
& & & \\
Observations & 6,710 & 6,710 & 6,710 \\
Individual controls? & No & Yes & Yes \\
Industry FE? & No & No & Yes \\
\hline
\end{tabular}

Notes: This table report OLS estimates of $\delta$ from equation (1), where the left-hand side variable is the natural logarithm of total pre-tax wage and salary income in 1999 dollars for technical professionals that changed detailed industry in the past year. All regressions are weighted using the CPS weights and include a full set of state and year fixed effects. Column 2 includes individual controls: a quartic in age and indicators capturing whether a worker has a college degree, marriage status, and sex. Statistical significance based on robust standard errors clustered at the state-level is denoted by: $* * * \mathrm{p}<0.01, * * \mathrm{p}<0.05, * \mathrm{p}<0.10$.

Table 4: Wages for professionals that changed industry after the MARA, 1977-2014.

workers in Michigan in the post-MARA period relative to workers changing industries in other states.

To examine relative wage changes, we use the natural logarithm of real total pre-tax wage and salary income as recorded in the CPS samples as the outcome variable in equation (1), limiting our sample to technical professionals that had changed detailed industry in the previous year. ${ }^{21}$ As documented in Table 4, Michigan workers that changed industry earned relatively lower wages after the introduction of MARA, though these changes are imprecisely estimated when excluding individual controls (column 1). However, controlling for individual characteristics, the estimates suggest that in the post-MARA period, technical professionals in Michigan earned considerably lower wages relative to observationally similar workers in other states, which also holds when detailed industry fixed effects are included (columns 2 and 3). While these results should be interpreted with care, due to the relatively few observations available and since we cannot precisely isolate the impact of CNCs on wages, they are broadly consistent with the hypothesis that enforceable CNCs led to unproductive labour market outcomes by worsening skill matches.

Moreover, because CNCs prevent technical professionals from working for competitors in the same technical field, they may hinder the reallocation of talent to innovative firms in expanding sectors of the economy, leading to a decline in the technological dynamism of a region. To examine this, we measure the share of workers in new jobs stemming from recent technological innovations following Lin

\footnotetext{
${ }^{21}$ For brevity and due to the relatively small number of observations we report results including all other states as a control group. However, results are broadly similar in magnitude using only adjacent states, states that did not enforce CNCs by the time of Michigan's reversal, and using a sample of states matched on pre-MARA characteristics respectively. We adjust nominal wages using the CPI provided in the CPS samples, converting incomes into 1999 USD.
} 


\begin{tabular}{lccc} 
& $(1)$ & $(2)$ & $(3)$ \\
\hline MARA $_{s} \times$ Post $_{t}$ & $-0.055^{* * *}$ & $-0.059^{* * *}$ & $-0.051^{* * *}$ \\
& $(0.005)$ & $(0.005)$ & $(0.005)$ \\
& & & \\
Observations & 17,624 & 17,624 & 17,624 \\
Individual controls? & No & Yes & Yes \\
Industry FE? & No & No & Yes \\
\hline
\end{tabular}

Notes: This table report OLS estimates of $\delta$ from equation (1), where the left-hand side variable is the probability that a technical professional was employed in a job that was created between 1977 and 1991. Column 2 includes individual controls: a quartic in age and indicators capturing whether a worker has a college degree, marriage status, and sex. Statistical significance based on robust standard errors clustered at the state-level is denoted by: $* * * \mathrm{p}<0.01, * * \mathrm{p}<0.05, * \mathrm{p}<0.10$.

Table 5: Professionals transitioning into new types of jobs after the MARA, 1977-1991.

(2011). By examining relative changes in the shifting of workers into new types of jobs before and after the introduction of MARA we can examine whether the post-MARA period was associated with lower dynamism. ${ }^{22}$

Table 5 shows a slowdown in the shifting of workers into new jobs in Michigan relative to other states in the post-MARA period. Our estimate in column 1 documents that after Michigan's reversal, the probability of a worker selecting into a new job decreased by roughly 6 percentage points. Column 2 further includes a set of individual controls, capturing the fact that educated workers were more likely to be observed in new jobs after 1980 (Lin, 2011; Berger and Frey, 2016), suggesting a similar decline for workers in Michigan relative to observationally similar workers in other states. In addition, to control for the possibility that differences in industrial composition may affect new job creation in the 1980s, we add a full set of detailed industry fixed effects in column 3. Even within detailed industries, however, the probability of transitioning into new types of jobs declined substantially for workers in Michigan. In sum, these results are suggestive of a decline in the technological dynamism of Michigan after the introduction of MARA, as fewer workers shifted into new jobs associated with technological advances in their field of work.

\footnotetext{
${ }^{22}$ We focus on the period 1977-1991, for which Lin (2011) documents the appearance of new occupational titles in the DOTs. However, our results remain similar if we examine worker selection into new types of jobs (created between 1977 and 1991) through 2014; the corresponding OLS estimates (s.e.) for the full sample are -0.081 (0.005), $-0.080(0.006)$, and -0.054 (0.005) respectively.
} 


\section{Conclusions}

Over the course of the 20th century, the rapid movement of talent from contracting companies to expanding innovators has shaped the economic trajectories of cities and regions throughout the United States. In particular, a frequently cited observation is that the technological dynamism of Silicon Valley stems from its legal infrastructure, making it impossible for employers to enforce noncompetes, allowing workers to move without restriction to the firms where there skills are most productive. In this paper, we exploit the fact that the state of Michigan inadvertently repealed its prohibition on CNC enforcement, with the introduction of MARA in 1985, to examine the causal impact of noncompetes on employee mobility and the technological dynamism of regions. Doing so, we document that workers increasingly left their technical field of expertise following the introduction of MARA: industry switching increased substantially faster in Michigan relative to other U.S. states. In tandem with more workers leaving their technical field, Michigan also experienced a decline in the shifting of workers into new employment opportunities, associated with the arrival of new technologies, in their technical field. We further show that workers leaving their industry after the introduction of MARA earned lower wages, implying that they shifted into jobs were their skills were less productive. These findings are also robust across various specifications, and consistent with the view that technical professionals that are subject to CNCs are more likely to leave their technical field to avoid lawsuits.

Our findings show how barriers to employee mobility can alter labour market outcomes for entire regions. While Silicon Valley continues to provide the engine of Schumpeterian growth in the United States, Michigan's mistaken decision to repeal its prohibition on CNC enforcement may have contributed to its decline. For policymakers seeking to foster technological dynamism, the prohibition of CNC enforcement is seemingly essential.

\section{References}

Acemoglu, D. (1997). Training and innovation in an imperfect labour market. The Review of Economic Studies, 64(3), 445-464.

Alterman, I. (1985). New era for covenants not to compete. Michigan Bar Journal, 258. 
Becker, G. S. (1975). Human Capital. New York: Columbia University Press.

Berger, T. and Frey, C. B. (2015). Industrial renewal in the 21 st century: evidence from us cities. Regional Studies, pages 1-10.

Berger, T. and Frey, C. B. (2016). Did the computer revolution shift the fortunes of us cities? technology shocks and the geography of new jobs. Regional Science and Urban Economics, 57, 38-45.

Bertrand, M., Duflo, E., and Mullainathan, S. (2004). How much should we trust differences-indifferences estimates? The Quarterly Journal of Economics, 119(1), 249-275.

Bleakley, H. and Lin, J. (2012). Thick-market effects and churning in the labor market: Evidence from us cities. Journal of Urban Economics, 72(2), 87-103.

Bullard, P. (1985). Michigan antitrust reform act: House bill 4994. third analysis. M.S.A. Sec.: 1-4.

Comin, D. and Hobijn, B. (2010). An exploration of technology diffusion. American Economic Review, 100(5), 2031-59.

Ellison, G., Glaeser, E. L., and Kerr, W. R. (2010). What causes industry agglomeration? evidence from coagglomeration patterns. The American Economic Review, 100(3), 1195-1213.

Fallick, B., Fleischman, C. A., and Rebitzer, J. B. (2006). Job-hopping in silicon valley: some evidence concerning the microfoundations of a high-technology cluster. The Review of Economics and Statistics, 88(3), 472-481.

Flood, S., King, M., Ruggles, S., and Warren, J. (2015). Integrated public use microdata series, current population survey: Version 4.0 [machine-readable database]. Minneapolis: University of Minnesota.

Garmaise, M. J. (2011). Ties that truly bind: Noncompetition agreements, executive compensation, and firm investment. Journal of Law, Economics, and Organization, 27(2), 376-425.

Gathmann, C. and Schönberg, U. (2010). How general is human capital? a task-based approach. Journal of Labor Economics, 28(1), 1-49. 
Gilson, R. J. (1999). Legal infrastructure of high technology industrial districts: Silicon valley, route 128, and covenants not to compete, the. NYUl Rev., 74, 575 .

Glaeser, E. L. (2005). Reinventing boston: 1630-2003. Journal of Economic Geography, 5(2), 119-153.

Goolsbee, A. and Klenow, P. J. (2002). Evidence on Learning and Network Externalities in the Diffusion of Home Computers. Journal of Law and Economics, 45(2), 317-43.

Griliches, Z. (1957). Hybrid corn: An exploration in the economics of technological change. Econometrica, 25(4), pp. 501-522.

Grübler, A. (1991). Diffusion: Long-term patterns and discontinuities. Technological Forecasting and Social Change, 39(1), 159-180.

Hansen, A. H. (1939). Economic progress and declining population growth. The American Economic Review, pages $1-15$.

Helsley, R. W. and Strange, W. C. (1990). Matching and agglomeration economies in a system of cities. Regional Science and Urban Economics, 20(2), 189-212.

Hsieh, C.-T., Hurst, E., Jones, C. I., and Klenow, P. J. (2013). The allocation of talent and us economic growth. Technical report, National Bureau of Economic Research.

Jacobs, J. (1969). The economy of cities. New York: Random House.

Jovanovic, B. and Lach, S. (1997). Product Innovation and the Business Cycle. International Economic Review, 38(1), 3-22.

Kambourov, G. and Manovskii, I. (2009). Occupational specificity of human capital*. International Economic Review, 50(1), 63-115.

Kindleberger, C. P. (1961). Obsolescence and technical change. Bulletin of the Oxford University Institute of Economics \& Statistics, 23(3), 281-297.

Levine, J. (1985). Covenants not to compete, nonsolicitation and trade secret provisions of stock purchase agreements. Michigan Bar Journal, 1248. 
Lifland, W. T. (1984). State antitrust law. Law Journal Seminars-Press.

Lin, J. (2011). Technological Adaptation, Cities, and New Work. Review of Economics and Statistics, 93(2), 554-574.

Malsberger, B. (1996). Covenants not to compete: A state-by-state survey. washington dc, the bureau of national affairs.

Mansfield, E. (1961). Technical change and the rate of imitation. Econometrica, 29(4), pp. 741-766.

Marshall, A. (1920). Principles of economics: an introductory volume.

Marx, M. (2011). The firm strikes back non-compete agreements and the mobility of technical professionals. American Sociological Review, 76(5), 695-712.

Marx, M., Strumsky, D., and Fleming, L. (2009). Mobility, skills, and the michigan non-compete experiment. Management Science, 55(6), 875-889.

Mincer, J. (1958). Investment in human capital and personal income distribution. The journal of political economy, pages 281-302.

Neal, D. (1995). Industry-specific human capital: Evidence from displaced workers. Journal of labor Economics, pages 653-677.

Parent, D. (2000). Industry-specific capital and the wage profile: Evidence from the national longitudinal survey of youth and the panel study of income dynamics. Journal of Labor Economics, 18(2), 306-323.

Poletaev, M. and Robinson, C. (2008). Human capital specificity: evidence from the dictionary of occupational titles and displaced worker surveys, 1984-2000. Journal of Labor Economics, 26(3), 387-420.

Pynnonen, B. D. (1994). Ohio and michigan law on postemplyoment covenants not to compete. Ohio St. $L J, \mathbf{5 5}, 215$.

Saxenian, A. (1996). Regional advantage. Harvard University Press.

Schumpeter, J. A. (1939). Business cycles, volume 1. Cambridge Univ Press. 
Sikkel, R. W. and Rabaut, L. C. (1985). Michigan takes a new look at trade secrets and non-compete agreements. Michigan Bar Journal, 1069.

Sullivan, P. (2010). Empirical evidence on occupation and industry specific human capital. Labour Economics, 17(3), 567-580. 